\title{
Синдром Сафо: клиническое наблюдение
}

\author{
Т.П. Макарова , Н.Н. Фирсова ${ }^{2}$ Х.М. Вахитов ${ }^{1}$ Ю.С. Мельникова ${ }^{1}$, Л.Р. Валиева ${ }^{2}$, О.И. Кузьмина
}

'ФГБОУ ВО «Казанский государственный медицинский университет» Минздрава России, Казань;

2ГАУЗ «Детская республиканская клиническая больница» МЗ РТ, Казань, Россия

\section{SAPHO syndrome: the clinical case}

\author{
T.P. Makarova', N.N. Firsova², H.M. Vakhitov' ${ }^{1}$,Yu.S. Melnikova, L.R. Valieva ${ }^{2}$, O.I. Kuzmina ${ }^{2}$ \\ ${ }^{1}$ Kazan State Medical University, Ministry of Health of Russian Federation, Kazan, Russia; \\ ${ }^{2}$ Children's Republican Clinical Hospital of the Ministry of Health of Tatarstan, Kazan, Russia
}

Синдром Сафо - комбинация гиперостоза грудиноключичного сочленения с пустулезом ладоней и/или подошв, пустулезным/ вульгарным псориазом или глубокими угрями; кроме того, отмечают поражение позвоночника, остеит и артрит, в том числе сакроилеит. В качестве триггерных факторов рассматривается роль инфекций, в частности Staphylococcus epidermidis, стрептококков и вирусов. С ними связывают аутоиммунный пост- или параинфекционный патогенез синдрома Сафо. Как и при прочих серонегативных спондилоартритах, значимым для патогенеза синдрома SAPHО является фактор переохлаждения.

Представлен клинический случай синдрома Сафо из группы серонегативных спондилоартритов. Показана особенность течения, сложность постановки диагноза у конкретного пациента и возможности таргетной терапии генно-инженерными препаратами.

Ключевые слова: дети, синдром Сафо, пустулезный артроостеит, серонегативные спондилоартриты, псориатический артрит, остеосклероз, диагностика, лечение.

Для цитирования: Макарова Т.П., Фирсова Н.Н., Вахитов Х.М., Мельникова Ю.С., Валиева Л.Р., Кузьмина О.И. Синдром Сафо: клиническое наблюдение. Рос вестн перинатол и педиатр 2017; 62:(5): 192-197. DOI: 10.21508/1027-4065-2017-62-5-192-197

Syndrome Sapho is a combination of hyperostosis of the sternoclavicular joint with pustulosis of the palms and/or plants, pustular/ vulgar psoriasis, or deep acne, which also celebrates spinal cord injury, osteitis and arthritis, including sacroiliitis. As trigger factors, the role of infections, such as Staphylococcus epidermidis, streptococci and viruses, is considered. They are associated with autoimmune post- or parainfectious pathogenesis of the SAPHO syndrome. As with the other seronegative spondyloarthritis important for the pathogenesis of SAPHO syndrome is a factor in hypothermia.

Presents a clinical case of the syndrome of Sappho from the group of seronegative spondyloarthritis. Features of the course, the complexity of diagnosis in a particular patient and the possibility of targeted therapy with genetically engineered drugs, are shown.

Key words: children, SAPHO syndrome, pustular arthroosteitis, seronegative spondylitis, psoriatic arthritis, osteosclerosis, diagnosis, treatment.

For citation: Makarova T.P., Firsova N.N., Vakhitov H.M., Yu.S. Melnikova, Valieva L.R., Kuzmina O.I. SAPHO syndrome: the clinical case. Ros Vestn Perinatol i Pediatr 2017; 62:(5): 192-197 (in Russ). DOI: 10.21508/1027-4065-2017-62-5-192-197

Ииндром Сафо (SАРНО-синдром, пустулезный артроостеит, spondyloarthritis hyperostotica pustulopsoriatica, а также синдром приобретенного гиперостоза, грудиноключичный гиперостоз) - комбинация гиперостоза грудиноключичного сочленения с пустулезом ладоней и/или подошв, пустулезным/ вульгарным псориазом или глубокими угрями; кро-

( К Коллектив авторов, 2017

Адрес для корреспонденции: Макарова Тамара Петровна - д.м.н., проф. кафедры госпитальной педиатрии с курсом поликлинической педиатрии Казанского государственного медицинского университета

Вахитов Хаким Муратович - д.м.н., доц., и.о. зав. кафедрой госпитальной педиатрии с курсом поликлинической педиатрии Казанского государственного медицинского университета

Мельникова Юлия Сергеевна - асс. кафедры госпитальной педиатрии с курсом поликлинической педиатрии Казанского государственного медицинского университета

420012 Казань, ул. Бутлерова, д. 49

Фирсова Наталья Николаевна - зав. кардиологическим отделением Детской республиканской клинической больницы

Валиева Лейсан Рифатовна - врач-педиатр консультативной поликлиники Детской республиканской клинической больницы

Кузьмина Ольга Ивановна - врач-педиатр консультативной поликлиники Детской республиканской клинической больницы 420138 Казань, Оренбургский тракт, д. 140 ме того, отмечают поражение позвоночника, остеит и артрит, в том числе сакроилеит [1]. Данное заболевание входит в группу серонегативных спондилоартритов. Впервые взаимосвязь поражения костно-суставного аппарата и кожи отметили в 1961 г. R. Windom и соавт. [2]. Аббревиатуру SAPHO предложили M.Kahn и A.Chamot в 1992 г.:

$\mathrm{S}$ - synovitis - воспаление синовии;

A - acne - угревая сыпь, или воспаление сальных желез $\mathrm{P}$ - pustulosis - пустулез, сыпь из пузырьков (пустул), заполненных гнойным содержимым;

$\mathrm{H}$ - hyperostosis - гиперостоз - уплотнение костной ткани;

$\mathrm{O}$ - osteitis - остеит, или воспаление костной ткани.

Эпидемиологических исследований по изучению распространенности синдрома Сафо не проводилось. В литературе описано около 250 случаев [3]. Следует отметить, что распространенность пустулеза в европейских странах достигает $0,5 \%$, а те или иные костно-суставные изменения на его фоне возникают в $15 \%$ случаев (несколько реже в Японии - 10\%).

Этиология и патогенез синдрома Сафо остаются предметом изучения. Ведущую роль играет генети- 
ческий фактор: в Европе до 30-40\% таких пациентов являются носителями HLA-B27. Доказана также ассоциация синдрома Сафо с гаплотипом В35+ и Cw4+ (отличие пустулезного артроостеита от псориатического артрита, при котором эту связь не наблюдают) [2].

В качестве триггерных факторов рассматривается роль инфекций, в частности Staphylococcus epidermidis, стрептококков и вирусов. С ними связывают аутоиммунный пост- или параинфекционный патогенез синдрома Сафо. Влияние персистенции возбудителей представляется таким же, как при реактивных артритах. Хронический рекуррентный мультифокальный остеомиелит («ювенильный Сафо») также носит реактивный или постинфекционный характер.

Как и при прочих серонегативных спондилоартритах, значимым для патогенеза синдрома Сафо является фактор переохлаждения. Кроме того, описано развитие у таких пациентов болезни Крона или неспецифического язвенного колита и в этих случаях речь может идти о сочетанной (перекрестной) форме спондилоартритов [3].

Клиническая картина. Кожные и костно-суставные проявления синдрома Сафо почти никогда не возникают одновременно. В $70 \%$ случаев первым признаком болезни является пустулез, изредка возможно его «присоединение» к артриту (артроостеиту). Свежие желтые пустулы при pustulosis palmoplantaris (ладонном и/или подошвенном пустулезе) могут выявляться на фоне старых - сухих, коричневатых. После очищения пустул остаются кратеры или чешуйки.

Кардинальным признаком синдрома Сафо является воспалительный асептический остеит, который ассоциируется с гиперостозом. В процесс вовлекаются хрящи и суставы грудной клетки. Остеит локализуется в ключицах, грудине, ребрах, что наряду с вовлечением в воспалительный процесс грудиноключичных и грудинореберных суставов, а также синхондроза между рукояткой и телом грудины создает картину симптомокомплекса передней грудной клетки. Клинически это выражается в появлении болей и припухлости грудино-реберных и грудино-ключичных суставов и/или области грудины. Также в патологический процесс могут вовлекаться кости тазового пояса, периферические суставы, позвоночник. Патологические изменения локализуются в различных областях скелета, но прежде всего в плоских костях. Воспалительный процесс в крестцово-подвздошных суставах возникает редко, и обычно он бывает односторонним.

Характерные кожные проявления: acne vulgaris (обычные угри), шаровидные угри, acne fulminans, ладонно-подошвенный пустулез, псориаз вульгарный, гидраденит (hydradenitis suppurrativa) [1, 2]. Пустула заполненный гноем интраэпидермальный пузырек. При ладонно-подошвенном пустулезе на воспаленном фоне возникают стерильные гнойнички, покрытые чешуйками; нередко они инфицируются. В части случаев pustulosis palmoplantaris рассматриваются как проявление атипичного псориаза - пустулезного.

Acne vulgaris (обычные угри) - поражение сальных желез, проявляющееся их гиперплазией, нарушением секреции и воспалением. Наиболее благоприятны acne comedonica, протекающие с гиперплазией, ороговением фолликулов и образованием комедонов; синдром Сафо на таком фоне не развивается. Тяжелее протекают acne conglobata - воспаленные конгломераты сальных желез, склонные к абсцедированию (acne papulopustulosa), образованию фистул и глубоких рубцов, особенно при молниеносном течении (acne fulminans).

K основным патогистологическим изменениям при пустулезном артроостеите относят необычное утолщение костных балок, остеосклероз и утолщение надкостницы, напоминающие болезнь Педжета, а также круглоклеточную инфильтрацию и изменения каймы остеоида, похожие на таковые при псориатическом артрите. Неизвестно, обязательно ли синовит / энтезит предшествуют костным изменениям при синдроме Сафо, или, как и при псориатическом артрите, анкилозирование суставов и периартикулярная оссификация могут развиться на фоне первичного поражения кости [1].

Диагностика. Клинико-анамнестические данные имеют первостепенное значение в постановке диагноза. Среди лабораторных изменений отмечают увеличение СОЭ, уровня С-реактивного белка и $\alpha_{2}$-глобулинов, возможны лейкоцитоз, анемия и повышение активности щелочной фосфатазы. Ревматоидный фактор в крови отсутствует, возможно выявление антигена HLA-B27.

Ранним рентгенологическим признаком поражения грудино-ключичного сочленения является фиброостеит - воспалительная энтезопатия, при которой отмечается веретено- или колбообразное прогрессирующее утолщение и остеосклероз проксимального конца ключицы. В дальнейшем возникает утолщение рукоятки грудины и анкилозирование сочленений грудины с I ребром и ключицей. Данные компьютерной томографии (КТ) нередко подтверждают деструктивный характер артрита обоих грудиноключичных сочленений. Это исследование особенно ценно возможностью дифференцирования артрита с костной опухолью (например, исключение остеоид-остеомы). Моноолигоартриты периферических суставов не являются деструктивными.

При рентгенологическом исследовании позвоночника у 1/3 больных удается выявить слабовыраженные синдесмофиты, признаки спондилодисцита, склерозирование тел позвонков, а в $10 \%$ случаев проявления сакроилеита. КТ позвоночника целесообразно проводить при выявлении типичных для синдрома Сафо рентгенологических изменений.

Реже встречаются следующие рентгенологические «находки»: склерозирование подвздошных 
и седалищных костей, деструктивный (эрозивный или остеолитический) симфизит с остеосклерозом лобковых костей, периостит и остеомиелит нижней челюсти, периоститы длинных трубчатых костей и костей реберно-поперечных сочленений. Контур периостальных наслоений помогает определить степень активности процесса: гладкий и четкий характерен для непрогрессирующего течения и стихания заболевания, «смазанный» и прерывистый - для его прогрессирования, а волнистость, бугристость и многослойность контуров свидетельствуют о неодновременности патологических изменений [1].

Отличия синдрома Сафо от серонегативных спондилоартритов следующие: при данном синдроме не бывает ярко выраженного спондилита с функциональной недостаточностью позвоночника; обычно не развивается коксит; нет системных проявлений (аортит, болезнь Берже, амилоидоз или воспалительные заболевания глаз); низкая частота выявления HLA B 27.

Лечение. Наиболее часто используются нестероидные противовоспалительные препараты. Назначение этих лекарственных средств показано больным с ревматическими заболеваниями с умеренными и выраженными болями, связанными с поражением суставов, позвоночника и околосуставных мягких тканей [4]. В тяжелых случаях применяются глюкокортикоиды в умеренных дозах, которые дают быстрый и яркий положительный эффект. У больных с высокой активностью и недостаточным эффектом нестероидных противовоспалительных препаратов можно использовать внутривенное введение высоких доз глюкокортикоидов в течение 1-3 дней («пульс-терапия») [5]. Суточную дозу следует снижать только после достижения частичной клинико-лабораторной ремиссии и существенного снижения выраженности как костно-суставных, так и кожных проявлений заболевания.

Локальная терапия, направленная на разрешение кожной сыпи, включая ароматические ретиноиды, не влияет на активность заболевания в целом и его исходы. Широко применяется лечение болезньмодифицирующими препаратами. Лучшим препаратом второй линии является метотрексат, который, как правило, способствует подавлению активности заболевания и сдерживанию прогрессирования. Эффективность таких лекарственных средств, как сульфасалазин, циклоспорин А, при синдроме Сафо сомнительна.

В последние годы при лечении синдрома Сафо применяются генно-инженерные биологические препараты. В качестве таргетной терапии назначают препараты, ингибирующие активность фактора некроза опухоли- $\alpha$ (ФНО- $\alpha)[6,7]$.

Представляем клинический случай из собственной практики.

Пациент М., 16 лет. Начало заболевания в июне 2016 г., когда впервые отмечено появление зудящих высыпаний на тыльной поверхности кисти обеих рук.
Консультирован дерматологом, поставлен диагноз: дерматит. Назначена местная терапия адвантаном.

Начиная с ноября 2016 г. появились распространенные гнойничковые высыпания на лице и туловище, болезненные при пальпации. С января 2017 г. отмечено повышение температуры тела до фебрильных цифр, общая слабость, гнойничковые выделения из ран, боли в мышцах спины при растягивании и напряжении. Ребенок госпитализирован в хирургическое отделение Центральной районной больницы с диагнозом: угри юношеские, конглобатные, инфильтративные, узловые, тяжелое течение; пиодермия.

При поступлении status localis: на коже лица, шеи, спины, волосистой части головы конглобатные пустулы с инфильтрацией, везикулы с гнойным содержимым, болезненные при пальпации. При бактериологическом посеве гнойного содержимого из раны лица выделен Staphilococcus aureus. Проведена антибиотикотерапия, иммунотерапия (иммуноглобулин человеческий №3, антистафилококковый иммуноглобулин №3), местная терапия.

В связи с отсутствием положительной динамики пациент был направлен на госпитализацию в хирургическое отделение Детской республиканской клинической больницы Минздрава Республики Татарстан (ДРКБ МЗ РТ) с диагнозом: абсцедирующий фурункулез спины; инфицированные конглобатные юношеские угри лица, туловища. Проведенные исследования: бактериологические посевы крови, мочи, из зева - патогенная флора не обнаружена.

В связи с болевым синдром в пояснично-крестцовой области проведена рентгенография пояснично-крестцовой области позвоночник в двух проекциях. Заключение: незначительный субхондральный склероз, грыжа Шморля $\mathrm{L}_{\mathrm{II}}$ позвонка. Осмотрен неврологом, поставлен диагноз: остехондроз поясничного отдела позвоночника с люмбосакралгией.

Проведена антибиотикотерапия цефтриаксоном, аксетином, ванкомицином и местная терапия. Выписан с незначительным улучшением кожного процесса. После выписки сохранялись субфебрильная температура тела, болевой синдром в нижних конечностях, присоединились жалобы на боли в левой половине грудной клетки и в области грудины. Амбулаторно назначен индометацин в свечах, на этом фоне отмечено уменьшение болевого синдрома.

В апреле 2017 г. пациент поступил в отделение кардиологии ДРКБ МЗ РТ с жалобами на повышение температуры тела до фебрильных цифр ежедневно, боли в левой ноге и ягодице, боли в левой половине грудной клетки, мышечную слабость, кожные высыпания.

Объективно на момент поступления: состояние средней степени тяжести за счет интоксикационного, кожного синдромов, выраженной астенизации. Сознание ясное. Телосложение астеническое. 
Таблица 1. Показатели общего анализа крови Table 1. The parameters of the blood analysis

\begin{tabular}{lcc}
\multicolumn{1}{c}{ Показатель } & $\mathbf{1 2 . 0 4}$ & $\mathbf{2 4 . 0 4}$ \\
\hline Лейкоциты, $10^{9} /$ л & 6,67 & 9,61 \\
Эритроциты, $10^{12} /$ л & 3,95 & 4,19 \\
Гемоглобин, г/л & 107 & 113 \\
Тромбоциты, $10^{9} / л$ & 290 & 311 \\
СОЭ, мм/ч & 58 & 36 \\
\hline
\end{tabular}

Питание пониженное. Кожные покровы с элементами сыпи, фурункулы на лице и спине с мокнутиями, на голенях - округлой формы высыпания с зудом (см. рисунок). Видимые слизистые чистые, влажные. Увеличены подмышечные, паховые лимфатические узлы, при пальпации безболезненные. Костно-мышечная система: деформация грудино-ключичных сочленений с обеих сторон, припухлость, слева пальпация болезненная. Ограничение наклона в пояснично-крестцовом отделе позвоночника (+20 см). Пальпация пояснично-крестцового отдела позвоночника безболезнена. Экссудативные изменения со стороны суставов не выражены. Ограничение внутренней ротации в тазобедренных суставах, больше слева. Патологические образования в мышцах не определяются. Сила мышц сохранена, самостоятельно приседает и встает, подъем по лестнице без затруднений. В легких дыхание везикулярное. Тоны сердца ясные, ритмичные. Живот мягкий, при пальпации безболезненный. Печень, селезенка не увеличены. Стул и диурез не изменены.

Результаты общего и биохимического анализов крови представлены в табл. 1, 2. В анализе крови на стерильность микрофлора не обнаружена. Антиген HLA-B27 в крови не выявлен. Содержание кальпротектина в кале 47 мкг/г (норма).

При сцинтиграфии склелета обнаружено повышение накопления радиофармпрепарата в проекции рукоятки грудины и верхней трети тела грудины, правого грудиноключичного соединения, передних отрезков IV ребра слева, IX ребра справа; повышение накопления радиофармпрепарата в проекции левых поперечных отростков ThII-X; симметричное накопление радиофармпрепарата в проекции нижней трети илеосакральных сочленений.

На серии магнитно-резонансных томограмм (МРТ) получены изображения обоих тазобедренных суставов, а также крестцово-подвздошных сочленений в корональной плоскости. Тазобедренные суставы симметричны, анатомическое соотношение суставных поверхностей сохранено. Костные структуры сформированы правильно, в области вертлужных впадин тазовых костей определяются единичные узуры, структура не совсем однородна за счет зон трабекулярного отека, который также активно визуализируется в области крыльев подвздошных костей и боковых массах
Таблица 2. Показатели биохимического анализа крови Table 2. The parameters of the biochemical analysis of blood

\begin{tabular}{lcc}
\hline \multicolumn{1}{c}{ Показатель } & $\mathbf{1 2 . 0 4}$ & $\mathbf{2 4 . 0 4}$ \\
\hline Общий белок, г/л & 73,0 & 81,0 \\
Билирубин, мкмоль/л & & \\
общий & 8,70 & 5,70 \\
прямой & 2,80 & 1,80 \\
непрямой & 5,9 & 3,9 \\
АЛТ, Е/л & 12,0 & 14 \\
\hline АСТ, Е/л & 30,0 & 23,0 \\
\hline АСЛО, Е/мл & $<50$ & $<50$ \\
СРБ, мг/л & 27,1 & 34,4 \\
\hline Іg G, г/л & 15,5 & \\
\hline Іg М, г/л & 1,22 & \\
\hline ЩФ, Е/л & & 74,0 \\
\hline С3 компонент комплемента, г/л & 1,5 & \\
\hline С4 компонент комплемента, г/л & 0,260 & \\
\hline КФК, Е/л & 49,0 \\
\hline Мочевина, ммоль/л & 3,20 & 3,70 \\
\hline РФ, Е/мл & $<20$ & $<20$ \\
\hline
\end{tabular}

Примечание. АЛТ - аланинаминотрансфераза, АСТ - аспартатаминотрансфераза, АСЛО - антистрептолизин О, СРБ - С-реактивный белок, IgG - иммуноглобулин $\mathrm{G}, \mathrm{IgM}$ - иммуноглобулин М, ЩФ - щелочная фосфатаза, КФК - креатинфосфокиназа, РФ - ревматоидный фактор.

крестца, преимущественно периартикулярно. Головки бедренных костей однородной структуры. Правильной округлой формы с умеренным субхондральным склерозом суставных поверхностей. Суставные щели не сужены, небольшое количество выпота в полости. Гиалиновый хрящ неравномерный, не дифференцируется в зоне узур. Костные разрастания по краям суставных поверхностей не отмечаются. Заключение: МР-признаки двустороннего коксатроза II-III степени, двустороннего сакроилеита.

На серии МР-томограмм пояснично-крестцового отдела позвоночника получены изображения на уровне $\mathrm{Th}_{0}-\mathrm{S}_{\mathrm{v}}$. Поясничный лордоз сохранен. Пояснично-крестцовый угол $-28^{\circ}$. Ширина позвоночного канала снижена. Определяются признаки дегидратации и легкого снижения высоты межпозвонковых дисков, а также дорсальные парамедианные с двусторонней латерализацией протрузии межпозвонковых дисков на уровне $\mathrm{L}_{\mathrm{III}}-\mathrm{L}_{\mathrm{IV}}-\mathrm{L}_{\mathrm{V}}-\mathrm{S}_{\mathrm{I}}-$ до 2,7 мм на уровне $\mathrm{L}_{\mathrm{III}}-\mathrm{L}_{\mathrm{IV}}, 2,5$ мм на уровне $\mathrm{L}_{\mathrm{IV}}-\mathrm{L}_{\mathrm{V}}$ (латеральные карманы субдурального пространства до 2 мм). Позвонки без костно-деструктивных изменений, признаки трабекулярного отека в теле $\mathrm{S}_{\mathrm{I}}$ позвонка, а также легкого субхондрального склероза замыкательных пластинок по всей области исследования. Определяются грыжи Шморля максимально до 6,6 мм по нижней поверхности $\mathrm{Th}_{\mathrm{X}}, \mathrm{Th}_{\mathrm{XI}}, \mathrm{L}_{\mathrm{III}}$ 

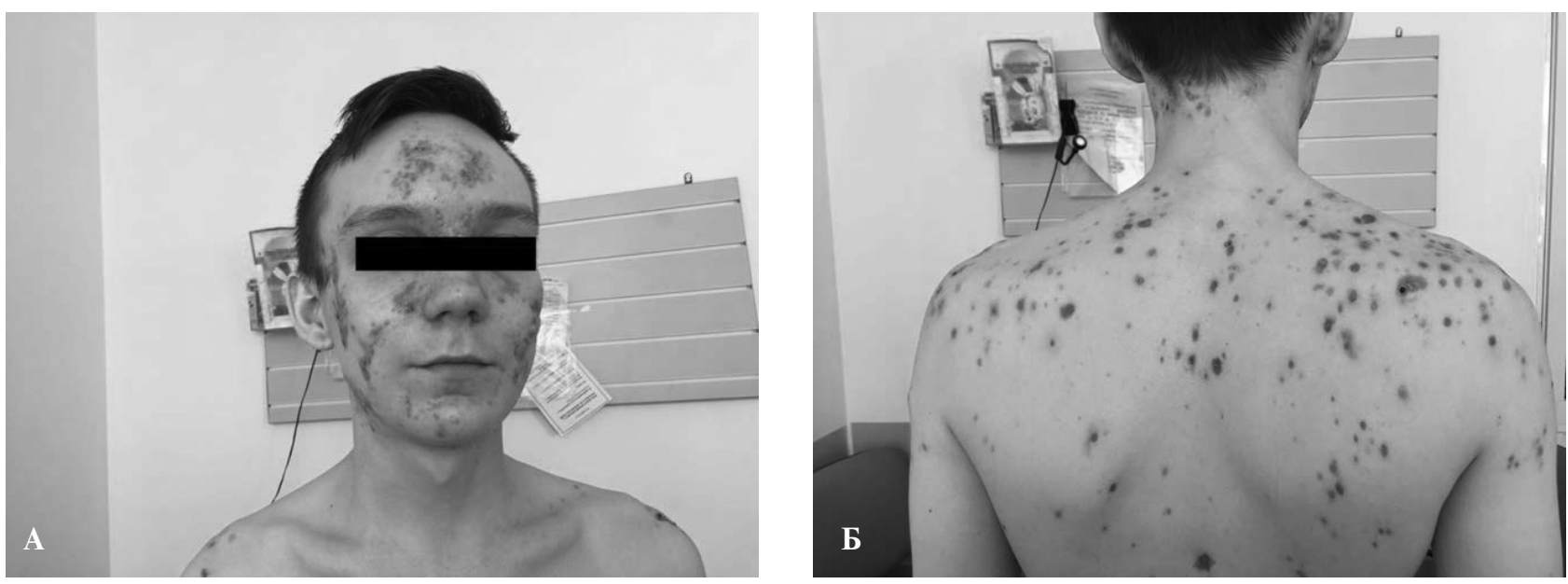

Рисунок. Acne vulgaris, acne papulopustulosa на лице (А), acne conglobate, acne papulopustulosa на спине (Б). Пациент М., 16 лет. Figure. Acne vulgaris, acne papulopustulosa on the face (A), acne conglobate, acne papulopustulosa on the back (B). Patient M. 12 years old.

позвонков, по верхней поверхности $\mathrm{Th}_{\mathrm{XI}}, \mathrm{L}_{\mathrm{II}}-\mathrm{L}_{\mathrm{IV}}$ позвонков. Визуализируются признаки spina bifida sacralis dorsalis $\mathrm{S}_{\mathrm{III}}-\mathrm{S}_{\mathrm{V}}$. Заключение: МР-признаки относительного стеноза позвоночного канала, умеренного спондилоартроза, трабекулярного отека тела $\mathrm{S}_{\mathrm{I}}$ позвонка, дегенеративно-дистрофические изменения грудно-поясничного отдела позвоночника в форме остеохондроза, протрузий межпозвонковых дисков на уровне $\mathrm{L}_{\mathrm{III}}-\mathrm{L}_{\mathrm{IV}}-\mathrm{L}_{\mathrm{V}}, \mathrm{S}_{\mathrm{I}}$, гипертрофии задней продольной связки на уровне $\mathrm{L}_{\mathrm{V}}-\mathrm{S}_{\mathrm{II}}$, узлов Шморля в телах $\mathrm{Th}_{\mathrm{x}}-\mathrm{Th}_{\mathrm{XI}}, \mathrm{L}_{\mathrm{II}}-\mathrm{L}_{\mathrm{IV}}$ позвонков.

Пациент консультирован ведущим научным сотрудником НИИ ревматологии РАН, руководителем детского отделения И.П. Никишиной. Поставлен диагноз: синдром Сафо. Рекомендовано: подбор терапии нестероидными противовоспалительными препаратами per os, при отсутствии положительной динамики в течение 3 мес - решение вопроса о назначении генно-инженерных биологических препаратов из группы ингибиторов ФНО- $\alpha$.

За время нахождения в стационаре пациент получил следующее лечение: режим палатный, диклофенак по 50 мг 3 раза в день, гастал по 1 таблетке (450 мг) 3 раза в день, омепразол по 25 мг на ночь, местная терапия.

На фоне лечения отмечена положительная динамика в виде уменьшения артралгического синдрома. Прихрамывание при ходьбе остаточное. Уменьшилась припухлость в области грудиноключичных сочлене-

\section{ЛИТЕРАТУРА (REFERENCES)}

1. Пузанова О.Г., Таран А.И., Трегуб Л.С. Синдром SAPHO. Внутренняя медицина 2007; 2. [Puzanova O.G., Taran A.I., Tregub L.S. The SAPHO Syndrome. Vnutrennyaya meditsina 2007; 2. (in Russ)]

2. Бадокин В.B. Синдром SAPHO. Научно-практическая ревматология 2004; 3: 61-65. [Badokin V.V. SAPHO syndrome. Nauchno-prakticheskaya revmatologiya 2004; 3: 6165. (in Russ)] ний, но сохраняется ограничение подвижности в пояснично-крестцовом отделе позвоночника. Кожный процесс стабилен, свежих высыпаний нет. Тенденция к снижению показателей гуморальной активности.

Диагноз при выписке: юношеский спондилоартрит (синдром Сафо) высокой степени активности. Хронический гастродуоденит в стадии неполной ремиссии. Рефлюкс-эзофагит 0-А степени. Двустворчатый аортальный клапан с недостаточностью аортального клапана II степени.

Ребенок находится на диспансерном наблюдении у кардиолога и педиатра. При отсутствии эффекта от терапии нестероидными противовоспалительными препаратами в течение 3 мес пациенту планируется назначение ингибиторов ФНО- $\alpha$.

Представленный клинический случай демонстрирует, что первым признаком синдрома Сафо явился пустулез ладоней с появлением кожных высыпаний в виде различных вариантов acne, что стало причиной постановки таких этапных диагнозов, как дерматит, юношеские угри, абсцедирующий фурункулез. Присоединение воспалительного процесса грудино-ключичных и грудино-реберных суставов, пояснично-крестцового сочленения, сопровождающегося синдромом артралгии в сочетании с кожным процессом, характерных для синдрома Сафо, данные КТ и МРТ позволили поставить правильный диагноз и назначить соответствующую терапию.

3. Киласониа Л.О., Гургенидзе И.А., Татошвили К.С. Случай диагностики синдрома SAPHO. Georgian Medical News 2001; 80 [Kilasonia L.O., Gurgenidze I.A., Tatishvili K.S., Diagnosis of the syndrome SAPHO Georgian Medical News. 2001; (80). (in Russ)].

4. Клинические рекомендации, утвержденные АРP в 2013г. Федеральные клинические рекомендации по «ревматологии» с дополнениями от 2016 г. http://rheumatolog.ru/ experts/klinicheskie-rekomendacii. [Clinical recommenda- 
tions. Federal clinical guidelines for "rheumatology" with additions from 2016. http://rheumatolog.ru/experts/klinicheskie-rekomendacii (in Russ)]

5. Агабабова Э.Р. Спондилоартриты как объект перспективных научных исследований в ревматологии. Избранные лекции по клинической ревматологии. Под ред. В.А. Насоновой, Н.В. Бунчука. М: Медицина 2001; 7482. [Agababova E.R. Spondyloarthritis as an object of promising scientific research in rheumatology. Selected lectures on

\section{Поступила 15.08 .17}

Конфликт интересов:

Авторы данной статьи подтвердили отсутствие конфликта интересов, финансовой или какой-либо иной поддержки, о которых необходимо сообщить. clinical rheumatology. V.A. Nasonova, N.V. Bunchuk (eds). Moscow: Meditsina 2001; 74-82. (in Russ)]

6. Furst D.E., Breedveld F.C., Kalden J.R, Smolen J.S., Burmester G.R., Bijlsma J.W. et al. Updatedconsensus statement on biological agents, specifically tumor necrosis factor a (TNF-a) blocking agents and interleukin-1 receptor antagonist (IL-1 ra), for the treatment of rheumatic diseases, 2004. Ann Rheum Dis 2004; 63 (Suppl II): 2-12. DOI: 10.1136/ ard.2004.029272

Received on 2017.08.15

Conflict of interest:

The authors of this article confirmed the absence conflict of interests, financial or any other support which should be reported. 